\title{
8
}
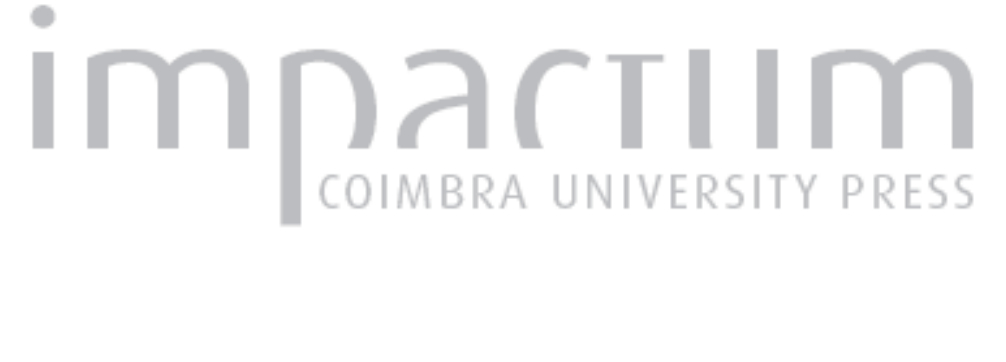

\section{Influência das crenças e atitudes rodoviárias enquanto determinantes da sinistralidade}

\author{
Autor(es): \\ Marques, Petra; Surrador, António; Jamal, Soraia; Fonseca, Maria José; \\ Freixo, Daniela \\ Publicado por: Associação Portuguesa de Riscos, Prevenção e Segurança \\ URL \\ persistente: \\ URI:http://hdl.handle.net/10316.2/36020 \\ DOI: \\ DOI:http://dx.doi.org/10.14195/1647-7723_19_22 \\ Accessed : $\quad$ 26-Apr-2023 16:05:56
}

A navegação consulta e descarregamento dos títulos inseridos nas Bibliotecas Digitais UC Digitalis, UC Pombalina e UC Impactum, pressupõem a aceitação plena e sem reservas dos Termos e Condições de Uso destas Bibliotecas Digitais, disponíveis em https://digitalis.uc.pt/pt-pt/termos.

Conforme exposto nos referidos Termos e Condições de Uso, o descarregamento de títulos de acesso restrito requer uma licença válida de autorização devendo o utilizador aceder ao(s) documento(s) a partir de um endereço de IP da instituição detentora da supramencionada licença.

Ao utilizador é apenas permitido o descarregamento para uso pessoal, pelo que o emprego do(s) título(s) descarregado(s) para outro fim, designadamente comercial, carece de autorização do respetivo autor ou editor da obra.

Na medida em que todas as obras da UC Digitalis se encontram protegidas pelo Código do Direito de Autor e Direitos Conexos e demais legislação aplicável, toda a cópia, parcial ou total, deste documento, nos casos em que é legalmente admitida, deverá conter ou fazer-se acompanhar por este aviso.

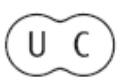




\section{territorium}

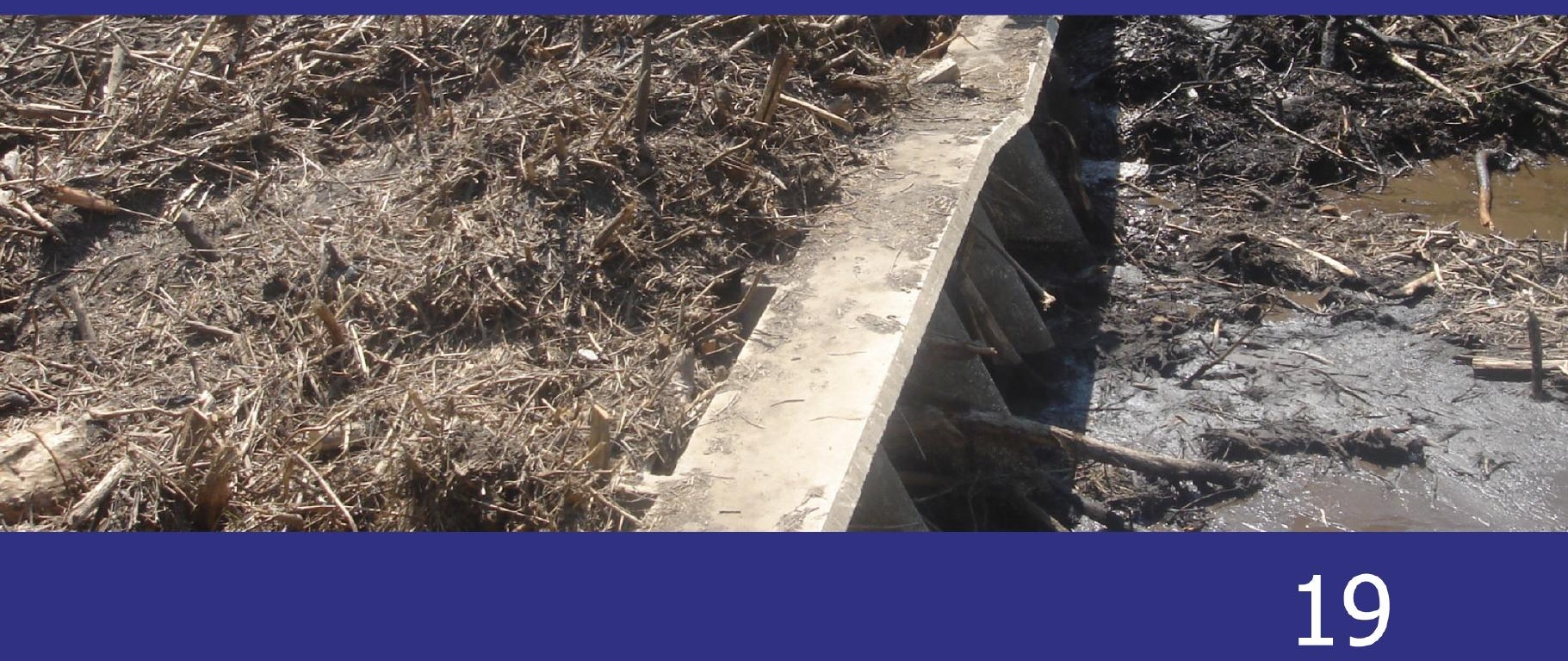

\section{Reequacionar o Conhecimento dos Riscos e das Catástrofes}

Revista da Associação Portuguesa de Riscos, Prevenção e Segurança 
Petra Marques

Centro de Psicologia da Força Aérea Portuguesa pammarques.marques@gmail.com

António Surrador

Centro de Psicologia da Força Aérea Portuguesa antonio.surrador@gmail.com

Soraia Jamal

Centro de Psicologia da Força Aérea Portuguesa jamal.soraia@gmail.com

Maria José Fonseca

Centro de Psicologia da Força Aérea Portuguesa maria.alvesfonseca@gmail.com

Daniela Freixo

Centro de Psicologia da Força Aérea Portuguesa danielafreixo@gmail.com

RESUMO

A sinistralidade rodoviária constitui um problema relevante nas sociedades modernas e tem despertado o interesse ao nível das diferenças individuais que potencialmente predizem os comportamentos de segurança na condução.

Pretende-se, com o presente estudo exploratório, averiguar a influência das crenças e atitudes rodoviárias, numa organização militar, enquanto variáveis determinantes da sinistralidade. Os resultados demonstram que a variável experiência de condução possui poder discriminativo sobre a sinistralidade e que as crenças não têm um impacto significativo nesta medida. São apresentadas orientações para futuros estudos.

Palavras chave: Crenças; atitudes; sinistralidade rodoviária.

\section{RESUMEN}

Influencia de las creencias y actitudes en la carretera como determinantes de la siniestralidad - La siniestralidad en las carreteras es un problema importante en las sociedades modernas y tiene despertado el interés al nivel de las diferencias individuales que potencialmente predicen los comportamientos de seguridad en la conducción.

Se pretende, con este estudio exploratorio, averiguar la influencia de las creencias y actitudes en la carretera, en una organización militar, en cuanto variables determinantes de la siniestralidad. Los resultados demuestran que la variable experiencia de conducción tiene poder discriminante sobre la siniestralidad y que las creencias no tienen un impacto significativo en esta medida. Son presentadas orientaciones para futuros estudios.

Palabras clave: Creencia; actitudes; siniestralidad en las carreteras.

\section{RÉSUMÉ}

Influence des croyances et des attitudes en tant que déterminants des accidents de la route - La sinistralité automobile est un problème pertinent dans les sociétés modernes et a suscité l'intérêt au niveau des différences individuelles que peuvent prévoir les comportements de sécurité dans la conduction. Cette étude exploratoire prétend comprendre l'influence des croyances et attitudes dans une organisation militaire comme variables déterminantes de la sinistralité. Les résultats révèlent que la variable expérience de conduite automobile a un pouvoir discriminatif sur la sinistralité et que les croyances n'ont pas d'impact significatif sur cette mesure. Les auteurs présentent des orientations pour des études futures.

Mots clés: Croyances, attitudes, sinistralité automobile.

* O texto deste artigo corresponde à comunicação apresentada ao II Congresso Internacional de Riscos e VI Encontro Nacional, tendo sido submetido para revisão em 01-06-2010, tendo sido aceite para publicação em 26-02-2011.

Este artigo é parte integrante da Revista Territorium, n. ${ }^{\circ} 19,2012,{ }^{\circ}$ RIscos, ISBN: 0872- 8941. 


\section{ABSTRACT}

Influence of beliefs and attitudes as determinants of road accidents - Traffic accidents are a major problem in modern societies and have been studied in the individual differences level, especially in those cases were they might predict the behaviour of safety driving. In this exploratory study we intend to investigate the influence of individual beliefs and attitudes towards traffic in a military organization, as variables that may determine road accidents. Results show that the driver experience variable has discriminative power over the rate of accidents (criteria), and that personal beliefs do not have a significant impact on criteria. Guidelines are presented for future studies.

Key words: Beliefs, attitudes, road accidents.

\section{Introdução}

A segurança rodoviária assumiu-se como um tema central nos principais debates na sociedade actual, ainda que nem sempre pelos melhores motivos.

Os elevados números da sinistralidade têm sido alvo de uma preocupação crescente por parte das entidades com intervenção nesta área como é o caso da Prevenção Rodoviária Portuguesa (S. SousA, 2005).

Verifica-se que é precisamente a faixa etária dos 20 a os 24 anos que se encontra sobre-representada nas estatísticas de acidentes rodoviários no ano 2000 (S. SOUSA, 2005).

Numa organização militar, onde existe um elevado número de condutores dentro da faixa etária supra referida, este tema ganha um lugar de destaque.

Neste sentido, é fundamental a compreensão e avaliação das crenças e atitudes dos condutores face à segurança rodoviária, enquanto condição que permita a promoção de uma mudança de atitudes conducente a comportamentos de segurança na condução.

Alguns estudos alertam para a necessidade de perceber o tipo e alcance das crenças rodoviárias nas populações de jovens condutores, por estas poderem apresentar especificidades inerentes a estas faixas etárias (A.I. GLENDON, 2005).

Paralelamente, outras linhas de investigação centraramse na compreensão dos comportamentos, atitudes e clima de segurança na classe profissional dos taxistas e verificaram que os indivíduos que adoptaram mais comportamentos de risco na condução também registaram uma atitude menos favorável face à segurança rodoviária e a tendência para a adopção de mais comportamentos de risco por parte dos condutores com menos experiência na condução (B. Rowland, J. Davey, J. Freeman e D. Wishart, 2007).

A perspectiva tripartida das atitudes desenvolve a ideia de que as atitudes na sua estrutura distinguem três componentes, a faceta afectiva, uma componente cognitiva, que inclui as crenças comportamentais e a componente conativa da qual faz parte uma intenção comportamental (M. Fishbein e I. AJzen, 1975). Os autores defendem que apesar de poderem estar intimamente correlacionadas, estes três aspectos correspondem a realidades psicológicas distintas.

Esta ideia de atitude como passível de ser declinada em três modos distintos, ainda que fortemente correlacionados, torna-se interessante para quem pretende modificar as atitudes dos outros (J.P. LEYENS e V. Yzerbyt, 1999), nomeadamente nas atitudes face à condução e segurança rodoviária. Assim, provocando mudanças em apenas um dos componentes de uma atitude, espera-se conseguir provocar mudanças nos outros dois (J.P. Leyens e V. YZERBYT, 1999).

Neste estudo tentou perceber-se quais as crenças cognitivas face à segurança rodoviária através da aplicação de um questionário.

No modelo hierárquico dos três componentes (M.J. Rosenberg e C.I. Hovland, 1960), a componente cognitiva das atitudes, baseia-se em respostas perceptivas e resulta em afirmações verbais de crença, daí que se inquiram as pessoas sobre as suas crenças nas temáticas da segurança rodoviária. É neste sentido que a linha teórica cognitivista defende que é a informação prévia que temos disponível sobre um assunto, ou seja, as crenças sobre determinada matéria que definem as nossas atitudes. Nesta abordagem, encontramos a teoria da acção reflectida de M. Fishbein e I. Ajzen (1975) que considera a atitude como um resultado do trabalho cognitivo de avaliação das crenças.

As nossas crenças sobre determinado assunto podem ter origem em informação obtida de forma directa (experiência pessoal) ou de forma indirecta, pela interacção com os outros, sendo que as crenças e atitudes construídas através experiência individual são mais estáveis e duradouras (R.H. FAZIo e M.P. ZANNA, 1981), pelo que se compreende a importância da experiência na condução e do seu impacto na formação de crenças e atitudes face à segurança rodoviária.

De acordo com a teoria de acção planeada, a acção humana é influenciada por 3 grandes factores: uma avaliação favorável ou desfavorável do comportamento (atitude face ao comportamento), a pressão social percebida para desempenhar ou não o comportamento (norma subjectiva), e a capacidade percebida 
para desempenhar o comportamento (controlo comportamental percebido).

Combinados, a atitude face ao comportamento, a norma subjectiva e a percepção do controlo comportamental, conduzem à formação da intenção comportamental (I. AJzen e A.S.R. MAnSTEAD, 2007). Como regra geral, quanto mais favorável for a atitude e a norma subjectiva e maior o controlo comportamental percebido, mais forte será a intenção da pessoa em desempenhar o comportamento em questão (I. Ajzen e N. Gilbert Cote, 2008).

De acordo com o modelo do valor esperado, a atitude de uma pessoa em relação a um objecto é determinada pelos valores ou avaliações subjectivas associadas ao objecto e pela força destas associações (I. AJzen e M. FishbeIn, 2008).

Nas teorias da acção reflectida (I. AJzen e M. Fishbein, 1980, citado por I. Ajzen e M. Fishbein, 2008) e na sua sucessora, teoria do comportamento planeado (I. AJZEN, 1988, 1991, citado por I. Ajzen e M. Fishbein, 2008), o objecto da atitude é o comportamento a ser previsto e as crenças relevantes lidam sobretudo com os resultados antecipados do comportamento. A estrutura básica da teoria do valor esperado assume que a atitude face a um comportamento é determinada por crenças salientes que dizem respeito às consequências de desempenhar esse comportamento, que são multiplicadas pela força das avaliações das crenças (I. AJzen e M. Fishbein, 2008).

A maioria dos investigadores concorda que a atitude pode ser descrita como uma "predisposição aprendida para responder consistentemente, de forma favorável ou desfavorável a um determinado objecto" (M. FISHBEIN e I. AJzen, 1975, p.6).

Enquanto que a atitude se refere a uma avaliação favorável ou desfavorável relativamente a um objecto, as crenças representam a informação que o indivíduo tem sobre esse objecto. Especificamente, a crença liga um determinado objecto a um atributo (M. FISHBEIN e I. AJZEN, 1975).

As intenções podem ser vistas como um caso especial das crenças, em que o objecto é sempre a própria pessoa e o atributo é sempre o comportamento. Tal como na crença, a força da intenção é indicada pela probabilidade subjectiva de que o sujeito irá desempenhar o comportamento em questão (M. FishBeIn e I. AJzen, 1975).

As crenças são a base da estrutura conceptual da visão teórica de M. Fishbeln e I. AJzen (1975). Através da observação directa ou da informação recebida de fontes externas, ou por meios de processos de inferência, os indivíduos aprendem ou formam um número de crenças sobre um objecto. Isto é, associam um conjunto de atributos ao objecto. Assim, forma crenças sobre ele próprio, sobre os outros, sobre comportamentos, eventos, entre outros. A totalidade das crenças dos indivíduos serve como base informacional que, em última análise, determina as suas atitudes, intenções e comportamentos (M. Fishbein e I. AJzen, 1975). Quando o objecto em causa é o próprio sujeito que se comporta de determinada maneira (atributos), reportamos à noção de auto-eficácia (A. BANDURA, 1977).

A ideia de que a auto-eficácia, definida por A. BANDURA (1977, p.3) como "as crenças individuais relativas às capacidades do indivíduo para organizar e executar os cursos de acção necessários para produzir determinados objectivos", está positiva e fortemente relacionada com o desempenho profissional, foi apoiada por diversos autores (e.g., J.A. Colquitt, J.A. Lepine, e R.A. Noe, 2000; A.D. Stajkovic e F. Luthan, 1998). Este aspecto poderá indiciar um efeito positivo da auto-eficácia sobre, especificamente, a mudança dos comportamentos.

No estudo de C.M. Axtell e colaboradores (2000), pode concluir-se, ainda que de forma indirecta, que a percepção de auto-eficácia influencia os indivíduos ao nível comportamental, uma vez que os autores defendem que este processo individual facilita a implementação de aprendizagens.

No presente estudo pretendemos averiguar, de forma exploratória, a influência das crenças e atitudes rodoviárias, enquanto determinantes da sinistralidade dos condutores de uma organização militar.

\section{Método}

\section{Participantes}

O estudo foi realizado numa instituição militar e a amostra é de conveniência, sendo que se pretendia obter a participação de indivíduos cuja função principal fosse a condução de viatura militares.

A amostra é constituída por 102 participantes cuja média de idades é 26,36 e varia entre 18 e 68 anos. Destes 91 eram do sexo masculino e 9 eram do sexo feminino. O tempo de experiência de condução varia entre os 0 anos e os 46 anos.

\section{Procedimento}

A entidade organizacional hierarquicamente responsável pela permissão para a realização de estudos na área comportamental foi contactada, tendo sido obtida uma autorização para a aplicação de questionários nas diversas unidades da organização militar em causa. Foram também contactadas as chefias intermédias, responsáveis pelos indivíduos e pela articulação do trabalho de cada um deles, no sentido de agendar um dia em que estivesse o maior número possível de condutores disponíveis para participarem no preenchimento dos questionários, uma vez que esta amostra foi recolhida 
em diversos pontos geográficos que distam fisicamente. Foi ainda realizado um pré-teste que permitiu obter informação sobre o tempo de preenchimento (em média 15 minutos para o preenchimento), averiguar sobre a compreensão dos itens do questionário e adequar a linguagem ao grupo e ao contexto. Neste sentido, foram realizadas ligeiras alterações ao instrumento.

A maioria dos questionários foi aplicada presencialmente, sendo que era dada aos participantes uma breve apresentação do estudo, as respectivas instruções sobre o preenchimento do questionário, assim como a garantia de confidencialidade e anonimato, apelando-se à participação dos sujeitos. Os dados foram recolhidos entre Setembro de 2009 e Fevereiro de 2010.

\section{Instrumentos e Operacionalização das Variáveis}

Os dados do presente estudo foram recolhidos utilizando uma metodologia quantitativa, nomeadamente um questionário de auto-relato. Os instrumentos utilizados foram previamente testados e validados.

Apresentamos seguidamente a operacionalização das variáveis em estudo.

\section{Auto-percepção}

A variável auto-percepção foi operacionalizada através da escala de "auto-percepção como condutor", com oito itens tendo uma escala de resposta de cinco pontos em que 1 corresponde a "Nada Eficiente" e 5 a "Muito eficiente", sendo 3 o ponto intermédio da escala.

\section{Crenças Rodoviárias}

A variável crenças rodoviárias foi operacionalizada através da utilização de um questionário com duas escalas. Na primeira escala, era solicitado aos inquiridos, recorrendo a uma escala de resposta de quatro pontos (entre 1-"Não tem nenhuma influência" e 4-"Evita de certeza a ocorrência de um acidente") que relatassem em que medida cada item contribuía para evitar o acidente. Na segunda escala, a tarefa dos inquiridos consistia em afirmar em que medida cada item contribuía para facilitar o acidente, através de uma escala de resposta semelhante à primeira, neste caso, considerando os factores que podem facilitar o acidente (entre 1-“Não tem nenhuma influência" e 4 "Facilita de certeza a ocorrência de um acidente”).
Estes questionários avaliam as crenças rodoviárias para os inibidores e facilitadores de acidentes e apresentam boas qualidades psicométricas (ver QUADRo I).

\section{Experiência de condução}

A variável experiência de condução foi operacionalizada através do número de anos que o indivíduo refere possuir categoria B (veículos ligeiros).

\section{Sinistralidade}

A variável sinistralidade foi operacionalizada, através do somatório do número total de acidentes em que o indivíduo refere ter tido culpa.

\section{Variáveis Sócio-Demográficas}

Foram incluídas no questionário algumas variáveis sóciodemográficas, caracterizadoras dos participantes em estudo (e.g., sexo, idade), bem como da sua situação relativamente à função em estudo (e.g., tempo de experiência na condução).

\section{Qualidades psicométricas dos instrumentos}

Procedeu-se à avaliação das qualidades psicométricas dos instrumentos usados para recolha dos dados, nomeadamente ao nível da validade de constructo e da consistência interna.

Neste sentido, desenvolveu-se uma análise factorial às variáveis: Auto-percepção, Crenças Rodoviárias - evitar acidente e Crenças Rodoviárias - facilitar acidente.

$\mathrm{Na}$ variável Auto-percepção, foram encontrados dois factores, que em conjunto explicam $62,44 \% \mathrm{da}$ variância, que foram denominadas: Auto-percepção dimensão instrumental (3 itens) e Auto-percepção dimensão cognitiva (4 itens). Cada um destes factores constituiu uma variável, como se verifica no Quadro II. Tendo sido retirado um item que pontuava igualmente para os dois factores ("Enquanto condutor eu sou...").

Para as duas escalas referentes às Crenças (evitar e facilitar) foi também feita uma análise factorial limitada a dois factores. Sendo que para cada uma das escalas foram apenas aproveitados 18 itens, que correspondiam

QUADRo I - Síntese: Instrumentos.

\begin{tabular}{|l|c|l|c|}
\hline \multicolumn{1}{|c|}{ Escala } & No itens & Exemplo de item & Alfa Cronbach \\
\hline Auto-percepção & 8 & $\begin{array}{l}\text { “Condução defensiva e cumprimento das } \\
\text { regras de segurança” }\end{array}$ & .85 \\
\hline Crenças Rodoviárias- evitar acidente & 35 & “Bom estado de conservação das vias” & .86 \\
\hline Crenças Rodoviárias- facilitar acidente & 35 & “Más condições climatéricas” & .81 \\
\hline
\end{tabular}


QUADRo II - Síntese: Variáveis.

\begin{tabular}{|l|c|l|c|}
\hline \multicolumn{1}{|c|}{ Variável } & No itens & \multicolumn{1}{|c|}{ Exemplo de item } & Alfa Cronbach \\
\hline Idade & & & \\
\hline Experiência & & & .79 \\
\hline Sinistralidade & & & .75 \\
\hline Auto-percepção dimensão instrumental & 3 & "Rapidez de reacção" & .86 \\
\hline Auto-percepção dimensão cognitiva & 4 & $\begin{array}{l}\text { "Condução defensiva e,cumprimento das } \\
\text { regras de segurança” }\end{array}$ \\
\hline Crenças Rodoviárias- evitar acidente & 18 & "Bom estado de conservação das vias" & .81 \\
\hline Crenças Rodoviárias- facilitar acidente & 18 & "Más condições climatéricas” & \\
\hline
\end{tabular}

ao factor "Crenças - evitar acidente" e ao factor "Crenças - facilitar acidente", respectivamente. Os restantes itens foram retirados das escalas devido ao critério de redundância dos itens, uma vez que o Alfa de Cronbach era, em ambos os casos, superior a .90 (R.F. DeVellis, 1991). O Quadro II apresenta a síntese das variáveis em estudo.

Seguidamente serão apresentados os resultados obtidos, através da utilização das variáveis acima descritas.

\section{Resultados}

A apresentação dos resultados irá obedecer à seguinte ordem: (1) estatística descritiva e correlações das variáveis em estudo; (2) análise do impacto das variáveis em estudo (idade, experiência de condução, a autopercepção como condutor e as crenças face ao que evita e o que facilita o acidente rodoviário) na sinistralidade (3) análise da capacidade que cada uma das variáveis em estudo tem em discriminar os sujeitos entre nunca ter tido um acidente e ter tido pelo menos um acidente com culpa.

\section{Estatística Descritiva e Correlações das Variáveis em Estudo}

A análise dos dados teve início pela estatística descritiva, apresentada no QUADRo III, que permite observar que a média da variável Sinistralidade é de 0.37 , ou seja, uma valor médio de menos de um acidente por individuo, variando entre 0 e 3 acidentes. Os indivíduos têm em média 7.04 anos de experiência de condução variando a experiência ente 0 e 46 anos de carta (no presente estudo os inquiridos com menos de 6 meses de carta foram considerados como não tendo experiência de condução). É possível ainda observar através dos valores de curtose e assimetria, que as quatro variáveis que derivaram das três escalas iniciais distribuem normalmente.

No QUADRo IV é possível observar as correlações entre as variáveis em estudo. É de verificar que nenhuma variável se correlaciona significativamente com a Sinistralidade.
Tal como era de esperar a idade correlaciona-se de forma significativa com a experiência de condução e também com ambas as variáveis de auto - percepção e as duas variáveis referentes às crenças na condução. As crenças evitar e facilitar o acidente correlacionam-se significativamente entre si, bem como as duas variáveis de auto - percepção.

O QuAdRo V apresenta os resultados da análise de regressão linear, que demonstra que nenhuma das variáveis em estudo tem um impacto significativo na sinistralidade $(\alpha=.05)$.

Os QUADRo VI e VII mostram a análise da regressão logística, que permitiu averiguar qual das variáveis em estudo tem a capacidade de discriminar os sujeitos entre nunca ter tido um acidente e ter tido pelo menos um acidente com culpa. Verifica-se que das variáveis em estudo, a única que discrimina significativamente os sujeitos face à sinistralidade é a experiência de condução $(p<.05)$.

O QUADRO VII mostra que a variável experiência de condução classificou correctamente $71.8 \%$ dos sujeitos.

Os resultados obtidos serão discutidos seguidamente.

\section{Discussão}

O principal objectivo deste estudo foi analisar o impacto das crenças rodoviárias e da "auto - percepção enquanto condutor" na sinistralidade. O presente estudo pretendeu igualmente perceber se as variáveis se correlacionavam entre si.

Tendo em vista estes objectivos, os resultados obtidos sugerem que não existe uma associação entre as crenças rodoviárias, ou a auto - percepção dos indivíduos enquanto condutores e a sinistralidade, no entanto mostram que existe uma relação entre a idade e a experiência na condução e a forma como os indivíduos se percepcionam enquanto condutores. Estes resultados vão ao encontro do que é referido na literatura sobre a origem da formação das crenças de forma directa (experiência pessoal, em particular experiência de 
RISCOS - Associação Portuguesa de Riscos, Prevenção e Segurança

QuAdro III - Estatística Descritiva das Variáveis em Estudo.

\begin{tabular}{|l|c|c|c|c|c|c|}
\hline \multicolumn{1}{|c|}{ Variáveis } & M & DP & Min & Max & Curtose & Assimetria \\
\hline Idade & 26.36 & 8.96 & 18 & 68 & -- & -- \\
\hline Experiência & 7.04 & 8.13 & 0 & 46 & -- & -- \\
\hline Sinistralidade & .37 & .69 & 0 & 3 & -- & -- \\
\hline Auto-percepção dimensão instrumental & 12.42 & 1.35 & 9 & 15 & .15 & .17 \\
\hline Auto-percepção dimensão cognitiva & 16.73 & 1.85 & 12 & 20 & -.54 & .07 \\
\hline Crenças rodoviárias-evitar acidente & 41.95 & 7.88 & 22 & 67 & .43 & .02 \\
\hline Crenças rodoviárias-facilitar acidente & 45.09 & 8.26 & 22 & 63 & .47 & -.65 \\
\hline \multicolumn{7}{|c|}{ Nota. M: média; DP: desvio-padrão; Min: mínimo; Max: máximo } \\
\hline
\end{tabular}

QuADRo IV - Correlações das Variáveis em Estudo.

\begin{tabular}{|l|c|c|c|c|c|c|c|}
\hline \multicolumn{1}{|c|}{ Variáveis } & 1 & 2 & 3 & 4 & 5 & 6 & 7 \\
\hline 1. Idade & 1 & & & & & & \\
\hline 2. Experiência & $.97^{* *}$ & 1 & & & & & \\
\hline 3. Auto-percepção dimensão instrumental & $.21^{*}$ & $.21^{*}$ & 1 & & & & \\
\hline 4. Auto-percepção dimensão cognitiva & $.40^{* *}$ & $.39^{* *}$ & $.57^{* *}$ & 1 & & & \\
\hline 5. Crenças rodoviárias-evitar acidente & -.06 & -.12 & .10 & -.08 & 1 & & \\
\hline 6. Crenças rodoviárias-facilitar acidente & -.03 & -.06 & .10 & -.05 & $.43^{* *}$ & 1 & \\
\hline 7. Sinistralidade & .00 & .16 & -.05 & -.05 & .00 & .04 & 1 \\
\hline \multicolumn{2}{|c|}{ Nota. ${ }^{*} \mathrm{p}<.05 ;{ }^{* *} \mathrm{p}<.01$} & & & \\
\hline
\end{tabular}

QUADRo V - Impacto das variáveis em estudo na sinistralidade.

\begin{tabular}{|l|c|c|c|}
\hline \multirow{2}{*}{} & \multicolumn{3}{|l|}{$\begin{array}{l}\text { Coeficientes } \\
\text { estandardizados } \mathrm{t}\end{array}$} \\
\cline { 2 - 4 } & Beta & $\mathrm{B}$ & Std. Error \\
\hline Idade & -.824 & -1.304 & .197 \\
\hline Experiência & .977 & 1.519 & .133 \\
\hline Crenças_Evitar & -.049 & -.360 & .720 \\
\hline Crenças_Facilitar & .051 & .393 & .696 \\
\hline $\begin{array}{l}\text { AP_dimensão } \\
\text { instrumental }\end{array}$ & -.039 & -.274 & .785 \\
\hline $\begin{array}{l}\text { AP_dimensão } \\
\text { Cognitiva }\end{array}$ & -.198 & -1.317 & .192 \\
\hline
\end{tabular}

Nota. $\mathrm{p}$ > .05; V.D: Número de acidentes com culpa.
QUADRo VI - Capacidade discriminativa das variáveis face à sinistralidade.

\begin{tabular}{|c|c|c|c|}
\hline & B & Sig. & $\operatorname{Exp}(\mathrm{B})$ \\
\hline Idade & -.417 & .081 & .659 \\
\hline Experiência & .510 & .049 & 1.665 \\
\hline Crenças_Evitar & .008 & .846 & 1.008 \\
\hline Crenças_Facilitar & -.002 & .961 & .998 \\
\hline AP_dimensão instrumental & -.361 & .152 & .697 \\
\hline AP_dimensão cognitiva & -.116 & .574 & .880 \\
\hline & & & \\
\hline
\end{tabular}

QUADRo VII - Capacidade discriminativa da variável experiência de condução face à sinistralidade.

\begin{tabular}{|c|c|c|c|c|}
\hline \multicolumn{2}{|c|}{ Observado } & Previsto & \\
\cline { 3 - 5 } & Acidentes & & $\begin{array}{c}\text { Percentagem } \\
\text { Correcta }\end{array}$ \\
\cline { 2 - 5 } & Não acidentado & Acidentado culpa & 92,6 \\
\hline \multirow{2}{*}{ Acidentes } & Não acidentado & 50 & 4 & 25,0 \\
\cline { 2 - 5 } & Acidentado culpa & 18 & 6 & 71,8 \\
\hline \multicolumn{2}{|c|}{ Percentagem Total } & \multicolumn{2}{|c|}{} \\
\hline
\end{tabular}


condução) ou de forma indirecta, pela interacção com os outros (condutores), sendo que as crenças e atitudes, neste caso referentes ao próprio - autopercepção, construídas através experiência individual são mais estáveis e duradouras (R.H. FAZIo e M.P. ZANNA, 1981). Assim percebe-se porque é que o sentimento de auto-eficácia (as crenças individuais respeitantes às capacidades e competências do próprio indivíduo para desempenhar o seu trabalho como condutor) se associa à experiência numa dada função (condução) (A. BANDURA, 1977). A ausência de impacto significativo de qualquer uma das variáveis em estudo na sinistralidade rodoviária, bem como a ausência de correlação significativa entre elas, poderá encontrar razão de ser nas limitações metodológicas deste estudo, podendo servir no entanto como base do desenvolvimento a investigação futura. A generalização dos resultados do presente estudo constitui outra das limitações metodológicas, ao nível da validade externa, visto a amostra ser de conveniência, constituída por indivíduos de uma instituição militar, com características únicas em termos estruturais e funcionais. Igualmente a utilização de uma medida directa (self-rating) para avaliar os comportamentos de segurança rodoviária, pode ter induzido alguns enviezamentos, mais especificamente no sentido de uma sobrevalorização ou desvalorização da mesma.

O facto de a variável "experiência de condução", conseguir discriminar de forma significativa os sujeitos, entre não ter tido nenhum acidente e ter tido pelo menos um acidente com culpa sugere a necessidade de futuros estudos.

\section{Conclusões gerais}

Os instrumentos usados para recolha dos dados apresentaram boas qualidades psicométricas, nomeadamente ao nível da validade de constructo e da consistência interna, ou seja a escala utilizada mede de facto as crenças que os indivíduos possuem em relação ao que pode facilitar e ao que pode evitar um acidente rodoviário e os itens estão fortemente correlacionados entre si.

Contudo, nenhuma das variáveis (idade, experiência de condução, a auto-percepção como condutor e as crenças face ao que evita e o que facilita o acidente rodoviário) em estudo se correlaciona significativamente com a sinistralidade rodoviária, nem tem um impacto significativo na sinistralidade.

Apenas a variável experiência de condução, consegue discriminar de forma significativa os sujeitos, entre não ter tido nenhum acidente e ter tido pelo menos um acidente com culpa.
Estes resultados fazem com que se levantem algumas hipóteses, nomeadamente, se outras variáveis, tal como uma formação estandardizada de um contexto militar, estarão a interferir na relação entre as variáveis em estudo; e/ou se os inquiridos estarão a condicionar as suas respostas, segundo o que pensam ser organizacionalmente e socialmente espectável.

Face ao que foi exposto no ponto anterior seria importante no futuro testar as hipóteses levantadas, no sentido de se perceber que outras variáveis estão presentes na relação entre as variáveis em estudo, e em que medida elas se fazem sentir nesta relação.

Seria igualmente importante averiguar em que medida a variável experiência de condução, consegue discriminar os sujeitos entre não terem tido nenhum acidente $\mathrm{e}$ terem tido pelo menos um acidente com culpa, por exemplo, se existirá um nível óptimo em termos de experiência de condução.

Finalmente, sugere-se ainda o prosseguimento da recolha de dados, no sentido de alargar a amostra, e verificar se desta forma se obtêm resultados e conclusões mais significativas.

\section{Referências Bibliográficas}

Auzen, I., \& Manstead, A. S. R. (2007). "Changing healthrelated behaviors: An approach based on the theory of planned behavior". In $\mathrm{K}$. VAN Den Bos, M. Hewstone, J. De Wit, H. Schut \& M. Stroebe (Eds.), The scope of social psychology: Theory and applications (pp. 43-63). New York: Psychology Press.

Ajzen, I., \& Gilbert Cote, N. (2008). "Attitudes and the prediction of behavior". In W. D. CRano \& R. PRISLIN (Eds.), Attitudes and attitude change (pp. 289-311). New York: Psychology Press.

Ajzen, I., \& Fishbein, F. (2008). "Scaling and testing multiplicative combinations in the expectancyvalue model of attitudes". Journal of Applied Social Psychology, 38, 2222-2247.

Axtell, C. M., holman, D. J., Unsworth, K. L., Wall, T. D., Waterson, P. E., \& Harrington, E. (2000). "Shopfloor innovation: Facilitating the suggestion and implementationofideas". JournalofOccupational and Organizational Psychology, 73, 265-285.

Bandura, A. (1977). "Self-efficacy: Toward a unifying theory of behavioral change". Psychological Review, 84 (2), 191-215.

Colquitt, J. A., Lepine, J. A., \& Noe, R. A. (2000), “Toward an Integrative Theory of Training Motivation: a Meta-Analytic Path Analysis of 20 years of 
Research", Journal of Applied Psychology, Vol. 85 (5), pp. 678-707.

Develus, R. F. (1991). "Scale development theory and applications". Newbury Park: Sage.

FAZIO, R. H., \& ZANNA, M.P. (1981). "Direct experience and attitude-behaviour consistency". In L. BERKOWITZ (Ed.), Advances in experimental social psychology. Vol. 14. New York: Academic Press.

Fishbein, M. \& A Azzen, I. (1975). "Belief, Attitude, Intention, and Behavior: An Introduction to Theory and Research". Reading, MA: Addison-Wesley.

Glendon, A. I. (2005). "Young drivers' attitudes towards risks arising from hazardous driving behaviours". In L. DoRn (Eds.), Driver behavior and training (pp. 193-206). Burlington: Ashgate.

Leyens, J. P. \& Yzerbyt, V. (1999). "Psicologia social". Lisboa: Edições 70.
Rosenberg, M. J. \& HOVLAND, C. I. (1960). "Cognitive, affective, and behavioral components of attitudes". In C. I. HOVLAND \& M. J. ROSENBERG (Orgs.), Attitude organization and change (114). New Haven, CT: Yale University Press.

Rowland, B., Davey, J., Freeman, J. \& Wishart, D. (2007). "A profile of taxi drivers' road safety attitudes and behaviours: is safety important?'. In Proceedings 3rd international road safety conference, Perth, WA.

Stajkovic, A. D., \& Luthan, F. (1998). "Self-efficacy and work related performance: a meta-analysis". Psychological Bulletin, 124 (2), 240-261.

SousA, S. (2005). "Intervenção na formação geral de condução. Análise psicológica", Vol. 1 (23), pp. 55-58. 